\title{
Efficiency and productivity change of public hospitals in Panama: Do management schemes matter?
}

Jose M. Cordero ( $\sim$ jmcordero@unex.es )

https://orcid.org/0000-0001-8783-6748

Agustín García-García

Universidad de Extremadura

Enrique Lau-Cortés

Universidad de Panama

Cristina Polo

Universidad de Extremadura

\section{Research}

Keywords: Hospitals, Efficiency, Productivity change, Malmquist, DEA, Ownership

Posted Date: July 16th, 2020

DOI: https://doi.org/10.21203/rs.3.rs-42430/v1

License: (c) (i) This work is licensed under a Creative Commons Attribution 4.0 International License. Read Full License

Version of Record: A version of this preprint was published at International Journal of Environmental Research and Public Health on August 15th, 2021. See the published version at https://doi.org/10.3390/ijerph18168630. 


\title{
Efficiency and productivity change of public hospitals in Panama: Do management schemes matter?
}

\author{
José M. Cordero $^{1 *}$, Agustín García-García ${ }^{1}$, Enrique Lau-Cortés ${ }^{2}$, Cristina Polo ${ }^{1}$ \\ ${ }^{1}$ Universidad de Extremadura, Av. Elvas s/n, 06006, Badajoz, Spain \\ 2 Universidad de Panamá, Campus Universitario Octavio Méndez Pereira, 3366, \\ Panamá 4, Panamá
}

\begin{abstract}
Background: In Latin American and Caribbean countries the main concern of public health care managers has been traditionally placed on problems related to funding, payment mechanisms and equity of access. However, more recently, there is a growing interest in improving the levels of efficiency and reducing costs in the provision of health services. In this paper we focus on measuring the efficiency of public hospitals in Panama, where no such studies have been conducted so far. One of the most interesting features of the public hospital system in this country is that there are two different management schemes that coexist, thus we can make a distinction between hospitals operating under the Social Security Fund (SSF) and those belonging to the Ministry of Health $(\mathrm{MoH})$.
\end{abstract}

Methods: Our dataset includes data about 22 public hospitals (11 for each model) during the period 2005-2015. We rely on the use of Data Envelopment Analysis and the Malmquist Productivity index to calculate technical efficiency and productivity change of hospitals. In addition, we also apply bootstrapping techniques to calculate confidence intervals for the obtained efficiency and productivity scores in order to obtain more robust results.

Results: We find that, until the period 2012-2013, the performance of hospitals belonging to different systems experienced a similar trend. However, during the last years of the evaluated period the hospitals operating under the Social Security Fund clearly outperformed Ministry's hospitals. The main explanation for these divergences seems to be the growth of technological change. Nevertheless, the use of bootstrapping to make statistical inferences reveals that some differences detected may not be significant.

Conclusion: We demonstrate that the results of traditional DEA and Malmquist index analyses need to be tested for statistical significance. Otherwise, the conclusions reached could be wrong.

Key words: Hospitals; Efficiency; Productivity change; Malmquist; DEA; Ownership

(*) Corresponding autor: E-mail: jmcordero@unex.es;

ORCID ID: https://orcid.org/0000-0001-8783-6748 


\section{Background}

During the last decades, the main priorities of health policies in Latin American and Caribbean (LAC) has been expanding health coverage and reducing health inequalities. The majority of these countries have experienced great improvements in both areas thanks to the significant increase in public health expenditure (around 25\% between 2000 and 2015), which is expected to continue in the future due to cost pressures arising from technological advances and growing and aging population [1]. This brings forward the need to promote policies that enhance efficiency of expenditures in the health sector, since efficiency gains can help contain future spending and contribute to raising the health status of the population.

This research focuses on the study of the health sector in Panama, where the public sector plays a predominant role in the financing ${ }^{1}$. One of the most characteristic features of the public health structure in this country is its dual nature, i.e. there are two parallel financing systems or management schemes that coexist: the Social Security Fund (SSF) and the Ministry of Health $(\mathrm{MoH})$. This fragmentation in the financing of healthcare is relatively common in Central American countries, where there is usually one social health insurance scheme mostly for the formal sector (SSF in this case) and also a national health system (MoH in Panama) that guarantees coverage for the poor and those in the informal labor market [2]. The poor coordination between both systems has generated important distortions due to the duplication of services offered, the asymmetry between the services offered or the problems of inequity that arise between the urban and rural areas. Therefore, for years, there has been a strong interest in incorporating structural improvements in the model with the aim of reducing costs and avoiding inefficiencies.

Our focus is placed at the hospital level, since it accounts for the largest proportion of expenditure in both management schemes. Specifically, we examine the performance of a sample of 22 hospitals over an eleven-year period (2005-2015), so that we can check whether belonging to one financing system or the other has influence on efficiency levels and their evolution over this period. To do this, it was necessary to collect a large

\footnotetext{
${ }^{1}$ Panama is the second country in the Central American region with the highest public sector participation in health financing.
} 
volume of information on the units evaluated, since the health system of this country did not have a transparent and accessible database, as is usual in most developed countries. Therefore, one of the main contributions of this work has been precisely the development of an analytical tool to capture the basic information needed to conduct an assessment of hospitals, which made it possible to create a unified and homogeneous register for each hospital for all the years studied.

In order to assess the operational efficiency of hospitals we rely on the nonparametric Data Envelopment Analysis (DEA) method, which has been extensively used in empirical studies in the health sector [3-6]. This technique provides a measure of the relative efficiency of organizational units according to their use of their resources and the outputs achieved without imposing any functional form on technology. Nevertheless, its application is usually restricted to studies using cross-sectional data for one year, thus it is unable to analyze how efficiency evolves over a period. When panel data is available, as in our case, the changes in the productivity of the units evaluated can be analyzed using Malmquist Productivity Indexes (MPI), which also use the DEA approach in their calculation. This method allows for decomposing productivity change into two factors: changes in production technology, reflecting the changes of the production frontier in the DEA analysis, and changes in technical efficiency of the evaluated units in different periods, frequently interpreted as the "catching up effect".

The MPI approach has also been used in many previous studies to assess the managerial performance of hospitals [7-10]. However, this approach has two main weaknesses. The first one comes from the fact that the decomposition that most of these studies use is only consistent with the average product notion of productivity, which is restricted only under the constant returns to scale technology $[11,12]$. In order to avoid this potential limitation, we apply the alternative approach proposed by Ray and Desli [13], which has been scarcely applied to decompose productivity change in the health sector. Its main advantage is that it allows us to calculate technical efficiency change levels under the assumption of variable returns to scale, thus we can identify an additional factor of productivity change, the change of scale efficiency. The second potential drawback of this method is that estimates of efficiency and productivity do not offer any information of the uncertainty, thus we cannot determine whether differences between estimates are statistically significant [14]. As a possible remedy to this problem, Simar and Wilson 
$[15,16]$ propose a bootstrapping procedure to accurately estimate the efficiency and productivity scores and confidence intervals that establish the desired statistical inferences. Despite this option is available, there are still quite a few studies that have conducted statistical testing of estimators in DEA and Malmquist indices in the assessment of hospitals [17-19]. In this paper, we demonstrate that the results of traditional DEA and Malmquist index analyses need to be tested for statistical significance; otherwise, the conclusions reached could be wrong.

This study is by no means the first to deal with either efficiency or productivity when comparing different types of hospitals using DEA and MPI. Actually, there is a growing body of research focused on examining the relationship between health financing systems and hospital efficiency [20-24] and also exploring the effects of ownership on hospitals' performance [25-31]. All these works have in common that they refer to hospitals operating in developed countries, mainly from Europe and North America [32]. In recent years there has been a certain growth in the number studies regarding this issue in developing countries [e.g. 33, 34]. However, the available empirical evidence on LAC countries is still very scarce. Among the main exceptions we can highlight the empirical study conducted by Arocena and García-Prado [35], which evaluates the performance of a sample of hospitals in Costa Rica, or the most recent ones by Gimenez et al. [36, 37], referred to Mexican and Colombian hospitals, respectively. Therefore, the present paper, focused on comparing the performance of Panamanian public hospitals operating under different financing and organizational systems, constitutes an important contribution within this area of research.

The remainder of this paper is structured as follows: Section 2 describes the three-stage methodology applied in this study, i.e. data envelopment analysis to calculate efficiency scores, Malmquist productivity indices to measure performance changes over time and bootstrapping procedures to calculate confidence intervals for the efficiency and productivity scores. Then, in Section 3, the data sample used and the variables selected are presented. The results of this study are presented and discussed in section 4 . Finally, Section 5 summarizes some concluding remarks. 


\section{Methodology}

Data Envelopment Analysis (DEA) is the most widely method used in the literature to measure hospital performance ${ }^{2}$. DEA is a linear programming technique that allows for the development of an efficiency frontier based on input and output data from a sample of units. One of the major reasons for the use of this technique is its flexibility, since it does not require the definition of a set of formal properties that must be satisfied by the set of production possibilities. The aim of the data envelopment method is to build an envelope that includes all the efficient units, together with their linear combinations, leaving the rest of the (inefficient) units below it. The method provides a measure of the relative efficiency of organizational units taking into account simultaneously multiple inputs and outputs. Units located on the frontier have an efficiency score of 1 (or 100 $\%$ ), while the distance of the inefficient units from the envelope provides a measure of their level of inefficiency.

The DEA can either be input- or output-oriented. In this paper input-oriented technical efficiency measures are calculated, thus the objective function minimizes the degree by which input factors proportionally have to be reduced in order to produce the same output in a technical efficient manner [39]. This model is defined as follows:

Min $\quad \theta_{0}$

s.a. $\quad \sum_{j=1}^{n} \lambda_{j} x_{i j} \leq \theta x_{i 0}$

$$
\begin{aligned}
& \sum_{i=1}^{n} \lambda_{j} y_{r} \gtrless_{j} y_{r 0} \\
& \sum_{j=1}^{n} \lambda_{j}=1 \\
& \lambda_{i} \geq \mathrm{C} \\
& j=1, \ldots, n \quad \mathrm{r}=1, \ldots, \mathrm{s} \quad \mathrm{i}=1, \ldots, \mathrm{m}
\end{aligned}
$$

\footnotetext{
${ }^{2}$ See Kohl et al. [38] for an excellent review of this literature.
} 
This model implicitly assumes variable returns of scale in production ${ }^{3}$. In other words, inefficient units are only compared with others that operate on the same scale. In this way, the technique is made more flexible by facilitating the analysis in those cases (very common) in which not all the units evaluated operate on a similar scale.

From the efficiency scores obtained with DEA, changes in productivity between two different time periods can be measured using the Malmquist Productivity Index (MPI). The formulation of this index was introduced by Caves et al. [40] and subsequently enhanced by Fare et al. [41]. Based on the concept of the output-oriented distance function (Shephard, 1970), it can be defined as ${ }^{4}$ :

$$
\operatorname{MPI}_{C}^{t}\left(\mathbf{x}^{t}, \mathbf{y}^{t}, \mathbf{x}^{t+1}, \mathbf{y}^{t+1}\right)=\frac{D_{C}^{t}\left(\mathbf{x}^{t+1}, \mathbf{y}^{t+1}\right)}{D_{C}^{t}\left(\mathbf{x}^{t}, \mathbf{y}^{t}\right)}
$$

Then, the geometric mean of the index can be defined by the following expression:

$$
\operatorname{MPI}_{C}\left(\mathbf{x}^{t}, \mathbf{y}^{t}, \mathbf{x}^{t+1}, \mathbf{y}^{t+1}\right)=\left[\frac{D_{C}^{t}\left(\mathbf{x}^{t+1}, \mathbf{y}^{t+1}\right)}{D_{C}^{t}\left(\mathbf{x}^{t}, \mathbf{y}^{t}\right)} \times \frac{D_{C}^{t+1}\left(\mathbf{x}^{t+1}, \mathbf{y}^{t+1}\right)}{D_{C}^{t+1}\left(\mathbf{x}^{t}, \mathbf{y}^{t}\right)}\right]^{1 / 2}
$$

where MPI can take values greater than 1, which implies that there has been growth in productivity, values equal to 1 , representing stagnation in productivity levels, or values less than 1, in which case the productivity of the units evaluated has declined with time. Furthermore, when using this approach, there are two main causes that can explain changes in the productivity levels of units: changes in technical efficiency (EC) (commonly known in the literature as the "catching up effect"), which indicates whether the units evaluated are moving closer or further away from their corresponding efficiency frontier between the periods evaluated and the technological change (TC), represented by the geometric mean of its magnitude, which approximates to what extent the units belonging the efficiency frontier have improved or worsened their productivity

\footnotetext{
${ }^{3}$ The DEA model assuming constant returns to scale is identical just without the convexity constraint: $\sum_{j=1}^{n} \lambda_{j}=1$

${ }^{4}$ The "C" suffix indicates that constant returns of scale (CRS) are being considered.
} 
between the periods studied [42]. In the specific case of hospitals, the former can be interpreted as the improvements derived from the diffusion of best-practice technology in the management of hospitals and it is attributable to technical experience, management and organization, while the latter results from innovations and the adoption of new technologies by best-practice hospitals [43]. The most common decomposition of the Malmquist index is proposed by Färe et al [44]:

$$
\begin{aligned}
M P I_{C}\left(\mathbf{x}^{t}, \mathbf{y}^{t}, \mathbf{x}^{t+1}, \mathbf{y}^{t+1}\right)= & \frac{D_{C}^{t+1}\left(\mathbf{x}^{t+1}, \mathbf{y}^{t+1}\right)}{D_{C}^{t}\left(\mathbf{x}^{t}, \mathbf{y}^{t}\right)} \times\left\{\left[\frac{D_{C}^{t}\left(\mathbf{x}^{t+1}, \mathbf{y}^{t+1}\right)}{D_{C}^{t+1}\left(\mathbf{x}^{t+1}, \mathbf{y}^{t+1}\right)} \times \frac{D_{C}^{t}\left(\mathbf{x}^{t}, \mathbf{y}^{t}\right)}{D_{C}^{t+1}\left(\mathbf{x}^{t}, \mathbf{y}^{t}\right)}\right]\right\}^{1 / 2} \\
& =E C\left(\mathbf{x}^{t}, \mathbf{y}^{t}, \mathbf{x}^{t+1}, \mathbf{y}^{t+1}\right) \times \mathrm{T} C\left(\mathbf{x}^{t}, \mathbf{y}^{t}, \mathbf{x}^{t+1}, \mathbf{y}^{t+1}\right) .
\end{aligned}
$$

This decomposition is based on the use of a production technology with constant returns of scale, through which we approach the notion of the average product. However, this definition can generate consistency problems when this assumption is not applicable, that is, if there are returns of scale in production [45]. Taking this argument as a reference, Färe et al. [44] redefined the efficiency change (EC) as

$$
\begin{aligned}
E C\left(\mathbf{x}^{t}, \mathbf{y}^{t}, \mathbf{x}^{t+1}, \mathbf{y}^{t+1}\right)=\left[\frac{D_{V}^{t+1}\left(\mathbf{x}^{t+1}, \mathbf{y}^{t+1}\right)}{D_{V}^{t}\left(\mathbf{x}^{t}, \mathbf{y}^{t}\right)}\right] \times\left\{\frac{D_{C}^{t+1}\left(\mathbf{x}^{t+1}, \mathbf{y}^{t+1}\right) / D_{V}^{t+1}\left(\mathbf{x}^{t+1}, \mathbf{y}^{t+1}\right)}{D_{C}^{t}\left(\mathbf{x}^{t}, \mathbf{y}^{t}\right) / D_{V}^{t}\left(\mathbf{x}^{t}, \mathbf{y}^{t}\right)}\right\} \\
=\operatorname{PEC}\left(\mathbf{x}^{t}, \mathbf{y}^{t}, \mathbf{x}^{t+1}, \mathbf{y}^{t+1}\right) \times\left[\frac{S E^{t+1}\left(\mathbf{x}^{t+1}, \mathbf{y}^{t+1}\right)}{S E^{t}\left(\mathbf{x}^{t}, \mathbf{y}^{t}\right)}\right] \\
=\operatorname{PEC}\left(\mathbf{x}^{t}, \mathbf{y}^{t}, \mathbf{x}^{t+1}, \mathbf{y}^{t+1}\right) \times S C A\left(\mathbf{x}^{t}, \mathbf{y}^{t}, \mathbf{x}^{t+1}, \mathbf{y}^{t+1}\right)
\end{aligned}
$$

where PEC represents the change in pure technical efficiency and SCA the efficiency of scale. Thus, the Malmquist index can also be defined as

$$
\begin{aligned}
\operatorname{MPI}\left(\mathbf{x}^{t}, \mathbf{y}^{t}, \mathbf{x}^{t+1}, \mathbf{y}^{t+1}\right)= & \operatorname{PEC}\left(\mathbf{x}^{t}, \mathbf{y}^{t}, \mathbf{x}^{t+1}, \mathbf{y}^{t+1}\right) \times S C A\left(\mathbf{x}^{t}, \mathbf{y}^{t}, \mathbf{x}^{t+1}, \mathbf{y}^{t+1}\right) \\
& \times \operatorname{TC}\left(\mathbf{x}^{t}, \mathbf{y}^{t}, \mathbf{x}^{t+1}, \mathbf{y}^{t+1}\right) .
\end{aligned}
$$


Based on this decomposition, Ray and Desli [13] proposed a new decomposition of the Malmquist productivity index in which a frontier with variable returns of scale is used as a reference:

$$
\begin{aligned}
\operatorname{MPI}\left(\mathbf{x}^{t}, \mathbf{y}^{t}, \mathbf{x}^{t+1}, \mathbf{y}^{t+1}\right)= & \operatorname{PEC}\left(\mathbf{x}^{t}, \mathbf{y}^{t}, \mathbf{x}^{t+1}, \mathbf{y}^{t+1}\right) \times S C H\left(\mathbf{x}^{t}, \mathbf{y}^{t}, \mathbf{x}^{t+1}, \mathbf{y}^{t+1}\right) \\
& \times \operatorname{PTC}\left(\mathbf{x}^{t}, \mathbf{y}^{t}, \mathbf{x}^{t+1}, \mathbf{y}^{t+1}\right)
\end{aligned}
$$

where

$$
\begin{aligned}
& \operatorname{PEC}\left(\mathbf{x}^{t}, \mathbf{y}^{t}, \mathbf{x}^{t+1}, \mathbf{y}^{t+1}\right)=\frac{D_{V}^{t+1}\left(\mathbf{x}^{t+1}, \mathbf{y}^{t+1}\right)}{D_{V}^{t}\left(\mathbf{x}^{t}, \mathbf{y}^{t}\right)} \\
& \operatorname{PTC}\left(\mathbf{x}^{t}, \mathbf{y}^{t}, \mathbf{x}^{t+1}, \mathbf{y}^{t+1}\right)=\left[\frac{D_{V}^{t}\left(\mathbf{x}^{t+1}, \mathbf{y}^{t+1}\right)}{D_{V}^{t+1}\left(\mathbf{x}^{t+1}, \mathbf{y}^{t+1}\right)} \times \frac{D_{V}^{t}\left(\mathbf{x}^{t}, \mathbf{y}^{t}\right)}{D_{V}^{t+1}\left(\mathbf{x}^{t}, \mathbf{y}^{t}\right)}\right]^{1 / 2}
\end{aligned}
$$

The change of scale factor can be broken down into the following terms:

$$
\begin{aligned}
& S C H\left(\mathbf{x}^{t}, \mathbf{y}^{t}, \mathbf{x}^{t+1}, \mathbf{y}^{t+1}\right) \\
& =\left\{\left[\frac{D_{C}^{t}\left(\mathbf{x}^{t+1}, \mathbf{y}^{t+1}\right) / D_{V}^{t}\left(\mathbf{x}^{t+1}, \mathbf{y}^{t+1}\right)}{D_{C}^{t}\left(\mathbf{x}^{t}, \mathbf{y}^{t}\right) / D_{V}^{t}\left(\mathbf{x}^{t}, \mathbf{y}^{t}\right)}\right] \times\left[\frac{D_{C}^{t+1}\left(\mathbf{x}^{t+1}, \mathbf{y}^{t+1}\right) / D_{V}^{t+1}\left(\mathbf{x}^{t+1}, \mathbf{y}^{t+1}\right)}{D_{C}^{t+1}\left(\mathbf{x}^{t}, \mathbf{y}^{t}\right) / D_{V}^{t+1}\left(\mathbf{x}^{t}, \mathbf{y}^{t}\right)}\right]\right\}^{1 / 2} \\
& =\left[\frac{S E^{t}\left(\mathbf{x}^{t+1}, \mathbf{y}^{t+1}\right)}{S E^{t}\left(\mathbf{x}^{t}, \mathbf{y}^{t}\right)} \times \frac{S E^{t+1}\left(\mathbf{x}^{t+1}, \mathbf{y}^{t+1}\right)}{S E^{t+1}\left(\mathbf{x}^{t}, \mathbf{y}^{t}\right)}\right]^{1 / 2}
\end{aligned}
$$

The change of scale efficiency component of the above equation is actually the geometric mean of two measures of change of scale efficiency. The first is defined with respect to the technology of period $t$ and the second with respect to the technology of period $t+1$.

In order to calculate efficiency scores, productivity indices and the different components we rely on DEA. With the aim of improving the accuracy of the estimations, we obtain confidence intervals for the different components of productivity by applying bootstrap procedures, thus we can make reliable statements concerning whether they are significant. Bootstrapping, introduced by Efron [46] and Efron and Tibshirani [47], has 
proven effective in examining the sensitivity of efficiency and productivity measures to sampling variation. This method is based on the assumption that for a sample of observations with an unknown data generating process (DGP), the DGP can be estimated by generating a bootstrap sample from which parameters of interest can be derived. The process involves using the original sample to construct an empirical distribution of the relevant variables by sampling the original data set repeatedly generating an appropriately large number (B) of pseudo-samples ${ }^{5}$. Then, relevant statistics such as means or standard deviations can be calculated by applying the original estimation process to the re-sampled data. Once we have a large and consistent estimator of the DGP, the bootstrap distribution will imitate the original sampling distribution. This implies that we can estimate the bias of each estimator, the bias corrected estimator and also confidence intervals ${ }^{6}$.

Regarding the estimation of confidence intervals for MIP, we use the smoothed bootstrap approach suggested by Simar and Wilson [15], which provides more accurate estimations than the traditional naïve bootstrap ${ }^{7}$. If the obtained bootstrapped confidence intervals do not include the number one, then the estimated MIP statistically significantly differs from unity, and therefore it is possible to be sure that there has been productivity growth (if smaller than 0 ) or deterioration (if greater than 0 ) is indicated.

\section{Data and variables}

Panama is a Central American country with a population of approximately 4 million people, most of whom are concentrated in urban areas. The country is divided into ten provinces (Bocas del Toro, Chiriquí, Coclé, Colón, Darién, Herrera, Los Santos, Panama, West Panama and Veraguas) with their respective local authorities and five comarcas populated by a variety of indigenous groups ${ }^{8}$. The country's income level is medium-high, with significant economic development associated with the transoceanic canal between the Atlantic and the Pacific. However, there are important problems in the distribution of wealth associated with health inequalities.

\footnotetext{
${ }^{5}$ In this study the process has been repeated 1.000 times $(B=1,000)$ to ensure adequate coverage of confidence intervals.

${ }^{6}$ See Simar and Wilson [48] for details.

${ }^{7}$ See [47] or [16] for a more detailed description of these methods.

${ }^{8}$ The indigenous population represents less than $5 \%$ of the total.
} 
The public health sector serves $90 \%$ of the population through two healthcare providers, the Social Security Fund (SSF) and the Ministry of Health $(\mathrm{MoH})$. The former is an institution that offers health care to the insured population (more than $85 \%$ of the inhabitants) and dependents through a network of comprehensive care services. On the other hand, the $\mathrm{MoH}$ has the mission of ensuring access to health services for the entire population and the whole territory, including rural areas with more difficult access. The health system of the country is organized according to the degree of complexity of the services provided, distinguishing three basic levels of care. The first one is mainly composed of different typologies of primary care centers; the second level includes area and regional hospitals and the third level is formed by national hospitals and national and supra-regional hospitals as well as several specialized hospitals on mental health, rehabilitation and oncology. Our focus is on the upper two levels, since most of the health budget is concentrated in hospitals. In total, Panama's public hospital network consists of 40 hospitals (26 belonging to the $\mathrm{MoH}$ and 14 to the SSF).

In order to conduct this research, it was necessary to build a database about Panamanian hospitals, since there was no formal register including data on the activities and services and available resources. This information had to be captured through a questionnaire designed specifically for the development of this research that was distributed to those responsible for the management of all public hospitals that are part of the system. Since we were interested in capturing information over a sufficiently long period of years, it was necessary to provide the support of expert staff in statistics and medical records in some cases, since the existing data were widely dispersed. Therefore, one of the main contributions of this work has been precisely the development of an analytical tool to capture the basic information needed to conduct an assessment of the efficiency and productivity of these hospitals over an extended period of time.

Although we would have liked to include all hospitals in our assessment, we had to exclude some of them for different reasons. First, we exclude specialized hospitals in order to make the sample more homogeneous. We were also forced to exclude some newly established hospitals from the analysis, because they have not been operating during the whole period evaluated. Finally, some hospital managers did not report data about some relevant variables, thus our sample was comprised of a total of 22 hospitals, whose names and main characteristics are shown in Table A1 included in the Appendix. 
It is worth mentioning that the hospitals included in the sample represent approximately $70 \%$ of total beds in the public hospital system and around $80 \%$ of the personnel, thus we consider our sample to be fairly representative of the total number of hospitals in the public health system.

Our database includes data about eleven years (2005-2015), thus the total sample consists of 242 observations $(22$ hospitals $x 11$ years $=242$ ). The distribution of hospitals included in the sample between the two existing management models is equal (11 are part of the Ministry's network and 11 belongs to the SSF). With regard to their geographical distribution, the sample includes information on most of the provinces ( 8 out of 10). The specific distribution of hospitals among the different provinces and management systems is shown in Table 1.

Table 1. Distribution by province and financial system of the hospitals in the sample

\begin{tabular}{|l|c|c|c|}
\hline \multicolumn{1}{|c|}{ Province } & Total & SSF & MoH \\
\hline Bocas del Toro & 3 & 3 & 0 \\
\hline Chiriquí & 2 & 1 & 1 \\
\hline Coclé & 2 & 1 & 1 \\
\hline Darién & 1 & 0 & 1 \\
\hline Herrera & 2 & 1 & 3 \\
\hline Los Santos & 3 & 0 & 3 \\
\hline Panama & 6 & 3 & 1 \\
\hline Veraguas & 3 & 2 & $\mathbf{1 1}$ \\
\hline \multicolumn{1}{|c|}{ Total } & $\mathbf{2 2}$ & $\mathbf{1 1}$ & \\
\hline
\end{tabular}

Our selection of variables was based on previous hospital efficiency studies [6, 38, 49, 50], but also taking into account the limitations of the data collected. As inputs, we selected the total number of beds as a proxy of capital and two variables representing human resources (medical and non-medical staff). As output variables, we use two quantitative indicators that are clearly linked to the intensity of resource consumption, such as the number of discharges and emergency services ${ }^{9}$.

Table 2 contains the main descriptive statistics for the whole sample, i.e. for the 242 observations available, and Table 3 reports these statistics distinguishing between

\footnotetext{
${ }^{9}$ Unfortunately, data about other potential variables representing hospitals' outcomes employed in other empirical studies, such as inpatient rates, re-admissions or nosocomial infections, were available only for a limited number of hospitals.
} 
hospitals under different financial systems. The high values of standard deviation shown in both tables reveal the existence of significant heterogeneity among hospitals, with very diverse sizes and wide variations in their resource endowment. It is noteworthy that the number of beds is much higher in Ministry's hospitals, although the volume of staff is slightly higher in centers belonging to the SSF. Likewise, the MoH's hospitals clearly surpassed SSF's ones in the two representative output variables. As expected, the average values recorded for emergency cases are clearly higher than those for discharges, since the former do not involve a process of hospitalization.

Table 2. Descriptive statistics for total sample observations

\begin{tabular}{|c|c|c|c|c|c|}
\hline \multicolumn{2}{|c|}{ Variables } & Mean & SD & Min & Max \\
\hline \multirow{3}{*}{ Outputs } & Discharges & 8,885 & 8,598 & 407 & 32,009 \\
\cline { 2 - 6 } & Emergencies & 52,153 & 36,082 & 2,717 & 171,744 \\
\hline \multirow{3}{*}{ Inputs } & Beds & 205 & 209 & 15 & 843 \\
\cline { 2 - 6 } & Medical staff & 111 & 173 & 5 & 1,021 \\
\cline { 2 - 6 } & Non-medical staff & 321 & 256 & 6 & 1,049 \\
\hline
\end{tabular}

Table 3. Main descriptive statistics for different financial systems

\begin{tabular}{|c|c|c|c|c|c|}
\hline \multicolumn{2}{|c|}{ Variables } & \multicolumn{2}{c|}{ SSF } & \multicolumn{2}{c|}{ MoH } \\
\hline \multirow{3}{*}{ Outputs } & & Mean & SD & Mean & SD \\
\cline { 2 - 6 } & Discharges & 6,178 & 6,183 & 11,593 & 11,464 \\
\hline \multirow{3}{*}{ Inputs } & Emergencies & 43,623 & 43,638 & 60,684 & 60,486 \\
\cline { 2 - 6 } & Beds & 175 & 176 & 234 & 230 \\
\cline { 2 - 6 } & Medical staff & 131 & 131 & 92 & 90 \\
\cline { 2 - 6 } & Non-medical staff & 338 & 341 & 303 & 302 \\
\hline
\end{tabular}

Table 4 shows the mean values of each variable for each year. In addition, Figure 1 illustrates their progression over the period. If we observe the evolution experienced by the two outputs throughout the period, we can see that discharges experienced a continuous decrease since 2007, while emergency care followed an increasing trend until 2012, with a brief decline thereafter. This phenomenon may be due in part to the increase in chronic diseases, which causes bed rotation to slow down and extend the period of hospitalization of patients, affecting the possibility of new admissions and decreasing the total number of hospital discharges in the period. With regard to the inputs, the volume of medical personnel is much lower than that of other workers. This gap has been maintained throughout the period studied, during which both staff numbers have increased significantly. The number of beds has remained constant over the eleven years studied in most hospitals, with only slight changes in some hospitals. 
Table 4. Average values of each of the variables included in the model (2005-2015)

\begin{tabular}{|c|c|c|c|c|c|c|c|c|c|c|c|c|c|}
\hline & & 2005 & 2006 & 2007 & 2008 & 2009 & 2010 & 2011 & 2012 & 2013 & 2014 & 2015 & $\begin{array}{c}\text { Percentage change } \\
\quad(2005-2015)\end{array}$ \\
\hline Outputs & Discharges & 8,749 & 9,028 & 9,288 & 9,076 & 8,925 & 9,131 & 8,821 & 8,906 & 8,623 & 8,642 & 8,552 & $-2.25 \%$ \\
\hline \multirow[b]{2}{*}{ Inputs } & Beds & 202 & 203 & 203 & 204 & 204 & 204 & 205 & 206 & 207 & 206 & 207 & $2.48 \%$ \\
\hline & Medical staff & 95 & 98 & 101 & 103 & 103 & 105 & 108 & 125 & 126 & 131 & 130 & $36.84 \%$ \\
\hline
\end{tabular}

Figure 1. Evolution of average values over the period

(a) Discharges

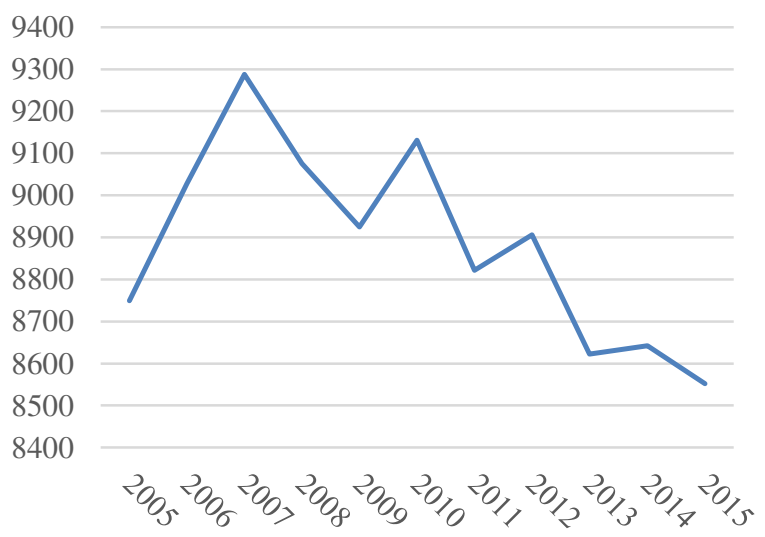

(b) Emergency services

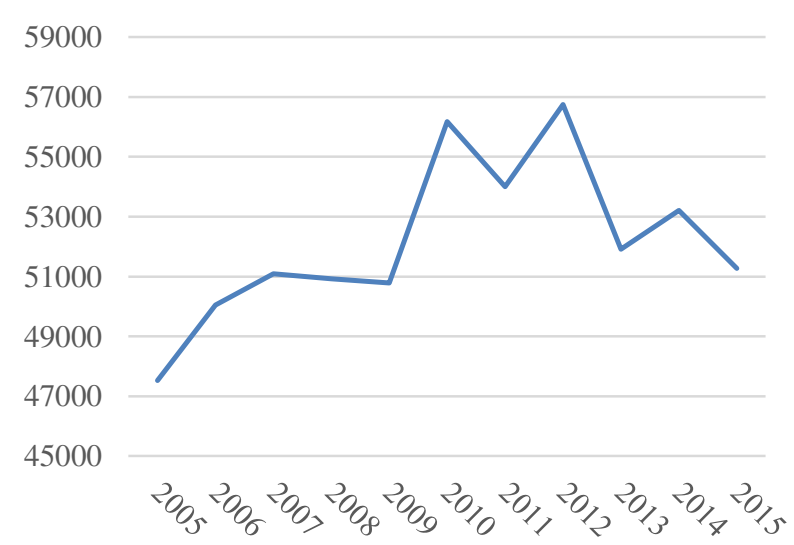

(c) Inputs

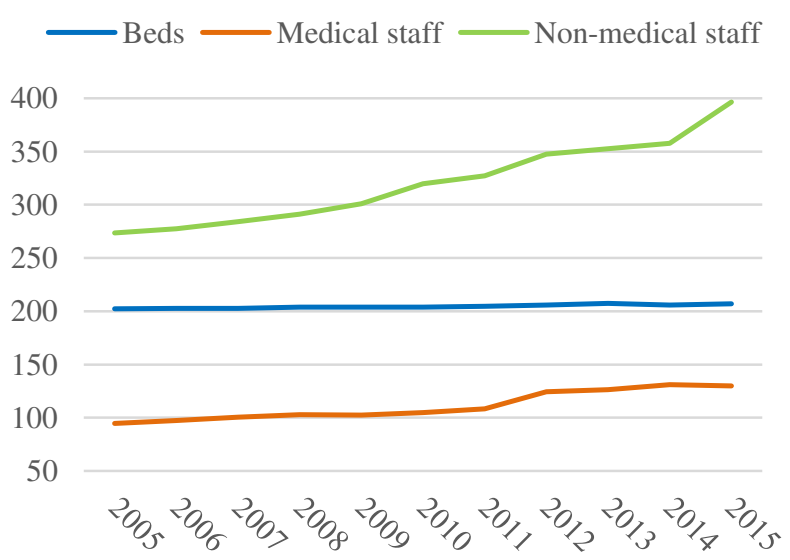




\section{Results}

This section shows the main results obtained after applying the methodologies presented in Section 2. The procedure followed for the estimation of the productivity indexes presented below is based on an inter-temporal analysis considering each pair of years, thus calculating ten different Malmquist indices. The first would reflect productivity between 2005 and 2006, the second between 2006 and 2007 and so on until the index reflecting the change between 2014 and 2015 is reached. Therefore, when analyzing the evolution of productivity in the period assessed, what is being represented is the average value of these ten indexes and not the index calculated between the first and the last year.

Table 5 provides a summary of the results for the whole sample of hospitals, including the descriptive statistics (mean, standard deviation, maximum and minimum) of MPI (second column) and their different components for the period 2005-2015. The third column shows the estimated values for the evolution of technical efficiency ("catch-up" effect), which can be decomposed into two components, pure efficiency and changes in scale (fourth and fifth columns). The sixth and following columns present the other component of the MPI, technological change, and its decomposition into pure technological change and scale variations.

Table 5. Descriptive statistics of the productivity index and its components (2005-2015)

\begin{tabular}{|c|c|c|c|c|c|c|c|}
\hline & MPI & EC & PEC & SEC & TC & PTC & STC \\
\hline Mean & 1.0253 & 1.0054 & 1.0144 & 0.9993 & 1.0242 & 1.0111 & 1.0300 \\
\hline SD & 0.0400 & 0.0253 & 0.0339 & 0.0142 & 0.0220 & 0.0330 & 0.0407 \\
\hline Min & 0.9788 & 0.9718 & 0.9769 & 0.9648 & 0.9904 & 0.9634 & 0.9775 \\
\hline Max & 1.1341 & 1.0770 & 1.1259 & 1.0319 & 1.0924 & 1.0863 & 1.1527 \\
\hline
\end{tabular}

As can be seen, the Malmquist productivity index has an average value of 1.0253, which indicates that the productivity of Panamanian hospitals experienced an average growth of around $2.5 \%$ during the period 2005-2015. This increase is mainly explained by technological change, while efficiency has hardly increased during the period. This result is of great interest and leads us to explore in greater depth the nature of this technological change. According to the mean values reported in the last two columns, 
the scale component seems to be the most relevant factor behind this technological improvement.

The bootstrap sample means offer further insight into the results discussed above. Table 6 shows the mean 95\% confidence intervals of MPI and its main components (EC and TC) for all hospitals and time periods ${ }^{10}$, which were derived through bootstrapping as described in the methodology section. The interpretation of the confidence intervals is straightforward. Since all of them contain unity, it is not possible to statistically conclude whether there is growth or deterioration. This demonstrates that we should be cautious when analyzing mean results from the original sample.

Table 6. Mean 95\% confidence intervals for MI, EC and TC for bootstrap sample

\begin{tabular}{|c|c|c|c|}
\hline & MPI & EC & TC \\
\hline Mean & 1.0253 & 1.0054 & 1.0242 \\
\hline Lower bound & 0.9911 & 0.8223 & 0.8534 \\
\hline Upper bound & 1.0704 & 1.2133 & 1.2613 \\
\hline
\end{tabular}

Figure 2 shows a graphic representation of the evolution experienced by each of the main components (efficiency and technological change) throughout the period 2005$2015^{11}$. Here we can see that, as mentioned above, the evolution of productivity is fundamentally linked to technological change. Both values follow an upward trend until 2008 and, after a small decline, they experienced remarkable growth in the early years of the new decade. The explanation for this result can be found in the investments made by several hospitals in these years with the aim of improving their infrastructures, which contributed to shifting the production frontier. However, in the last years of the period there is a certain divergence between them, as the MPI grows driven by EC, while the TC remains almost constant. It is also worth noting that efficiency change presents values very close to the unit in the first years and, subsequently, falls significantly until 2011, when it starts a continuous growth until the end of the period. These

\footnotetext{
${ }^{10}$ The values for the EC and TC decomposition considering scale effects as well as the values estimated for every year are available upon request. They are not shown here in order to save space.

${ }^{11}$ Table A2 included in the Appendix reports the specific values of MPI and its components for each of the different years under evaluation.
} 
improvements registered in technical efficiency denote upgraded organizational factors associated with the use of inputs to be able to increase the level of outputs.

Figure 2. Evolution of the Malmquist Index and its main components (2005-2015)

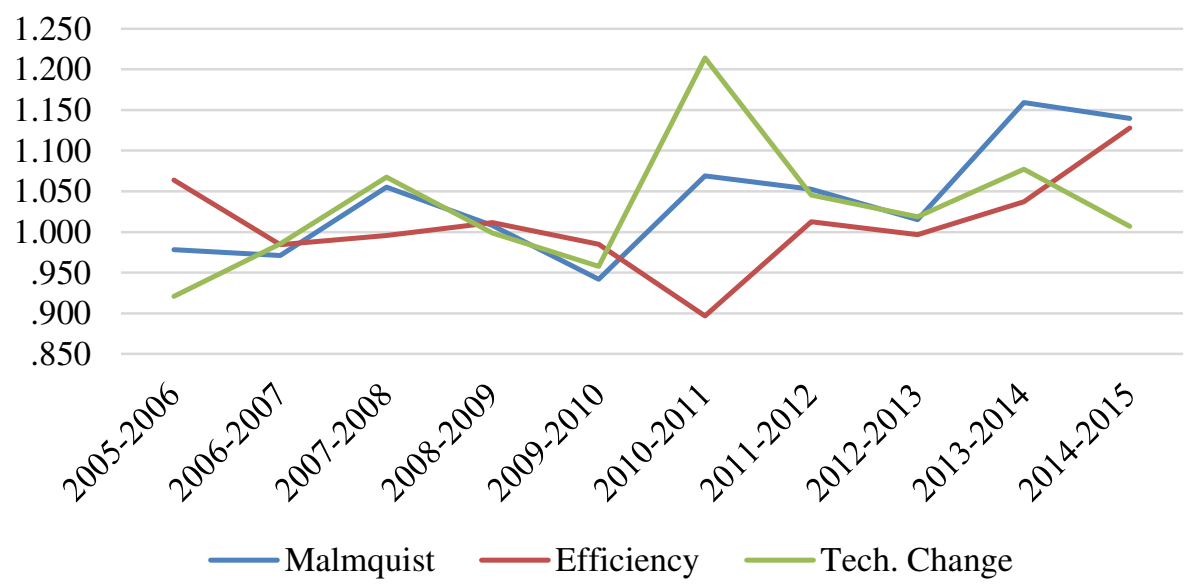

If we focus on the comparison between the two management models, the descriptive statistics reported in Table 7 show that hospitals belonging to the SSF outperform MoH's hospitals throughout the period studied according to the MPI values. We can also see that this advantage is mainly due to technological changes, since average efficiency growth has been very low in both systems. In contrast, the average growth recorded by the SSF hospitals in TC is twice the average increase registered by the Ministry's hospitals, whose growth is explained solely by factors of scale, while in the SSF hospitals it is attributable to both scale and pure technological change.

Table 7. Differences in descriptive statistics by type of management (2005-2015)

\begin{tabular}{|c|c|c|c|c|c|c|c|c|}
\hline & & MPI & EC & PEC. & SEC & TC & PTC & STC \\
\hline \multirow{4}{*}{ SSF } & Mean & 1.0365 & 1.0093 & 1.0175 & 0.9993 & 1.0365 & 1.0208 & 1.0348 \\
\cline { 2 - 9 } & SD & 0.0470 & 0.0208 & 0.0279 & 0.0081 & 0.0281 & 0.0348 & 0.0469 \\
\cline { 2 - 9 } & Min & 0.9836 & 0.9732 & 0.9769 & 0.9858 & 0.9904 & 0.9767 & 0.9869 \\
\cline { 2 - 9 } & Max & 1.0924 & 1.0489 & 1.0685 & 1.0154 & 1.0924 & 1.0863 & 1.1227 \\
\hline \multirow{3}{*}{ MoH } & Mean & 1.0141 & 1.0015 & 1.0028 & 0.9997 & 1.0185 & 1.0006 & 1.0248 \\
\cline { 2 - 9 } & SD & 0.0297 & 0.0296 & 0.0164 & 0.0192 & 0.0127 & 0.0291 & 0.0341 \\
\cline { 2 - 9 } & Min & 0.9788 & 0.9718 & 0.9833 & 0.9648 & 0.9967 & 0.9634 & 0.9775 \\
\cline { 2 - 9 } & Max & 1.0860 & 1.0770 & 1.0473 & 1.0319 & 1.0412 & 1.0451 & 1.0850 \\
\hline
\end{tabular}


Again, the values of the confidence intervals of MPI and its main components (EC and TC) for bootstrap sample reported in Table 8 allow us to be more precise in the interpretation of results. The MIP of hospitals belonging to SSF shows that there was significant progress at the 5\% level, as the confidence interval ranges from 1.0008 to 1.0919. Nevertheless, the confidence intervals for EC and TC for this group of hospitals both include unity. Therefore on it is not possible to statistically conclude that the MPI growth experienced by those hospitals can be attributed to technological change. As for the Ministry's hospitals, all intervals contain unity, thus we cannot make statements about whether they experienced growth or not during the period.

Table 8 . Mean $95 \%$ confidence intervals for MI, EC and TC by type of management

\begin{tabular}{|c|c|c|c|c|}
\hline & & MPI & EC & TC \\
\hline \multirow{3}{*}{ SSF } & Mean & 1.0365 & 1.0093 & 1.0298 \\
\cline { 2 - 5 } & Lower bound & 1.0008 & 0.8262 & 0.8473 \\
\cline { 2 - 5 } & Upper bound & 1.0919 & 1.2359 & 1.2749 \\
\hline \multirow{3}{*}{ MoH } & Mean & 1.0141 & 1.0015 & 1.0185 \\
\cline { 2 - 5 } & Lower bound & 0.9827 & 0.8185 & 0.8595 \\
\cline { 2 - 5 } & Upper bound & 1.0489 & 1.1908 & 1.2477 \\
\hline
\end{tabular}

Figures 3-5 show the evolution experienced by the productivity indexes and their main components (EC and TC) over the years, distinguishing between hospitals belonging to each financing model. In Figure 3 we can notice that the evolution of MPI shows a similar trend for both systems until 2012, when a large gap opened between them as a result of the greater growth experienced by SSF hospitals, while the Ministry's hospitals suffer a slight drop followed by some stagnation. The main explanation for these divergences observed in the last years of the period can be found in the evolution of technological change (TC), as shown in Figure 5. Thus, it can be seen that the effects of the investments made by the SSF hospitals managed to vary their trend towards growth in the last few years analyzed, while in the Ministry's hospitals a constant deterioration of this component can be seen from 2011 onwards. The analysis of the evolution of the components also allows us to appreciate that the efficiency change (EC) had a negative trend in both models until 2011. Since then there has been a notable growth in both as well, although it has reached a higher level in SSF hospitals. 
Figure 3. Evolution of MPI by type of management

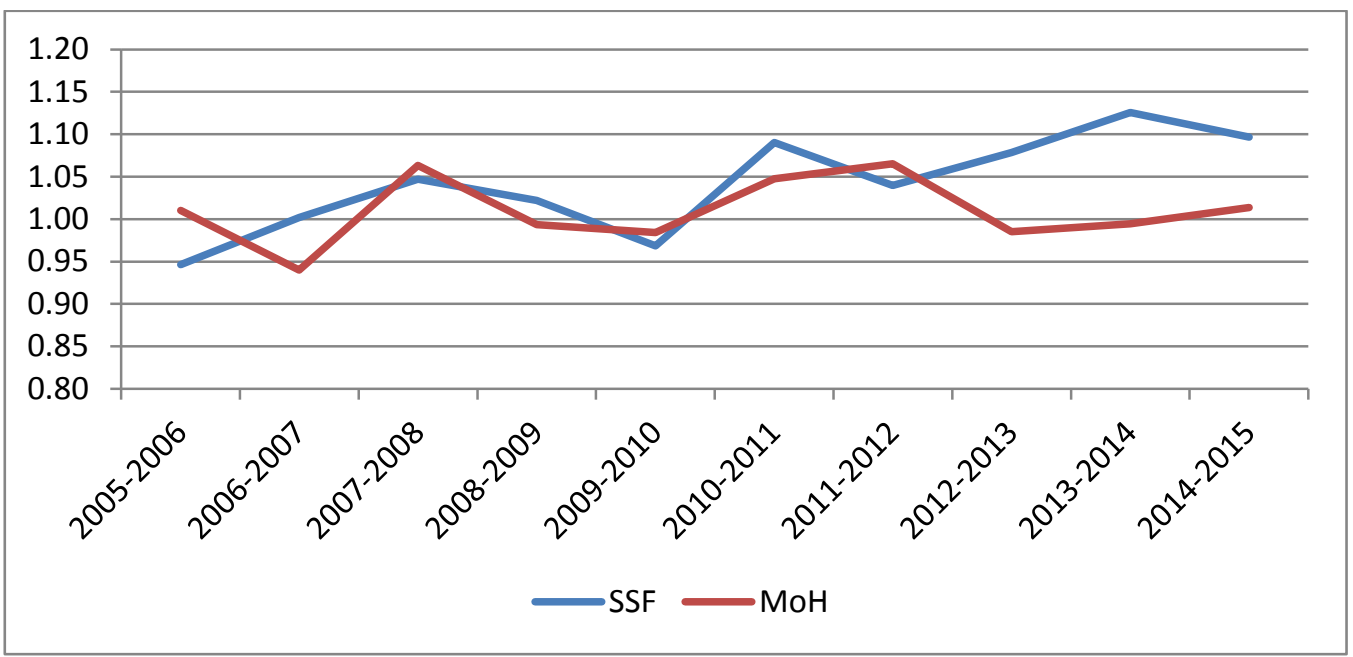

Figure 4. Evolution of EC by type of management

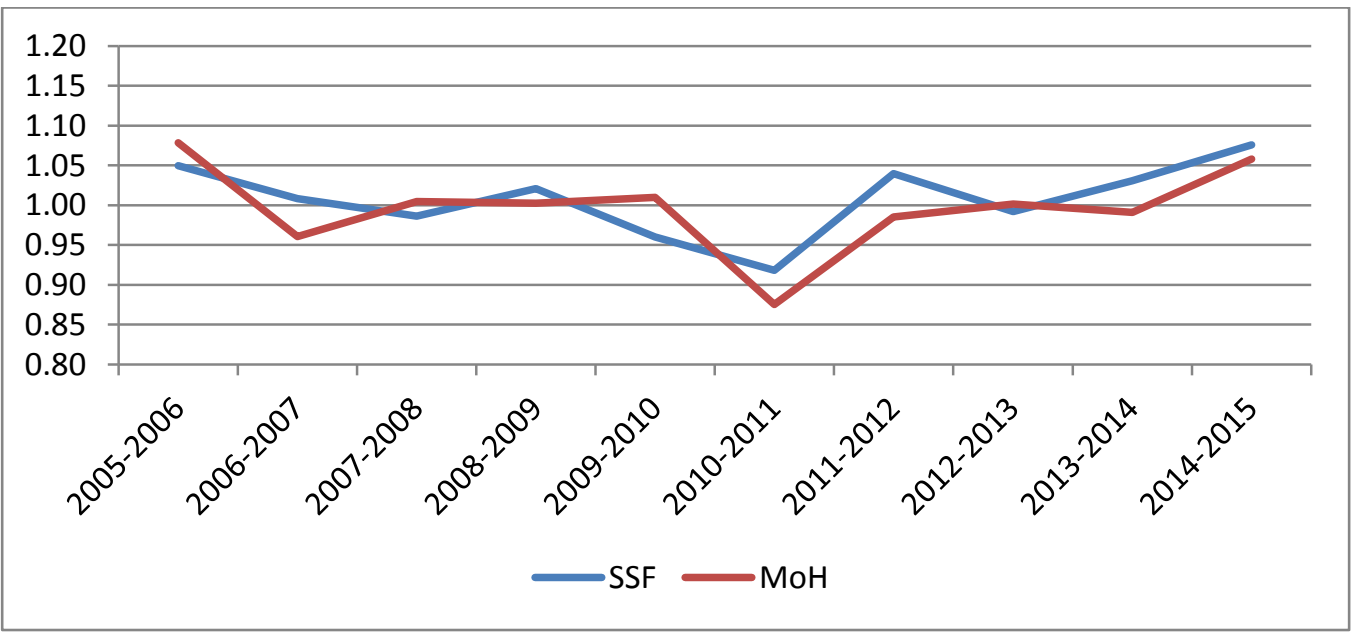

Figure 5. Evolution of TC by type of management

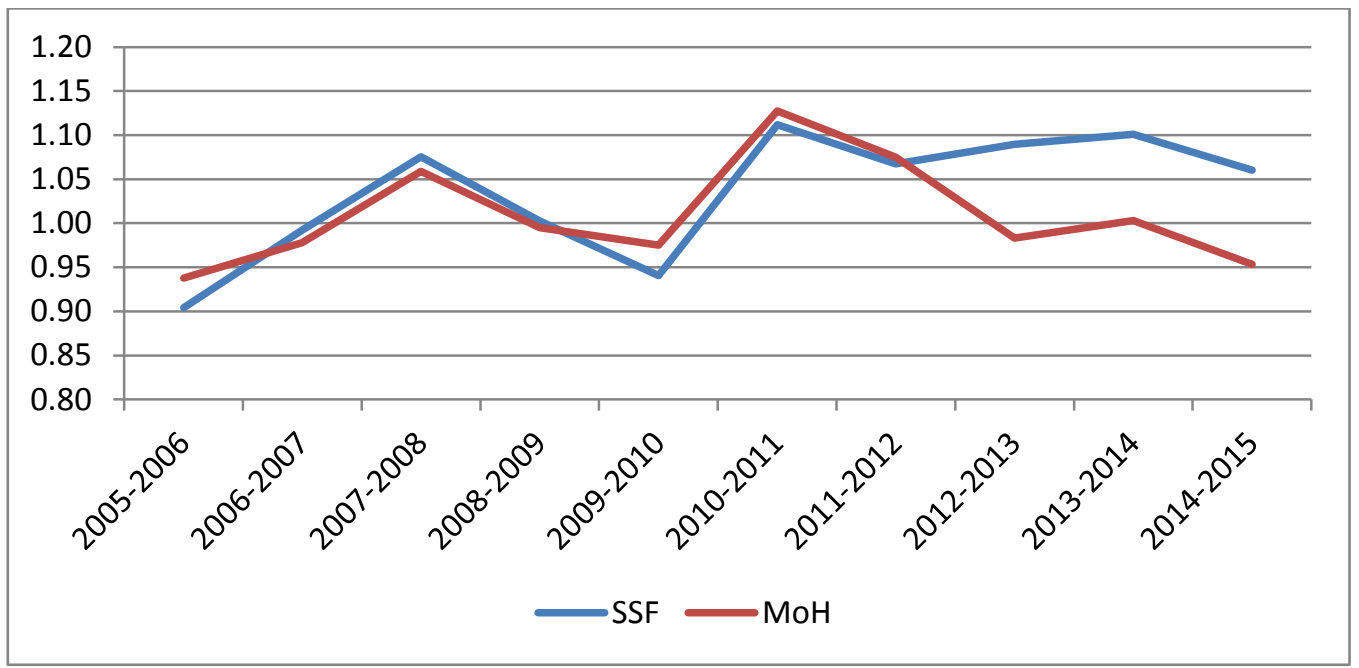


Finally, in Table 9 we provide the mean values of MPI and their components for each hospital throughout the whole period. Moreover, the confidence intervals estimated through bootstrapping for MPI, EC and TC in order to account for statistical significance are also presented. Since hospitals are ranked according to the average MPI growth experienced over these years, we can notice that 7 of the first 9 belong to the SSF, while most of the Ministry's hospitals are in the middle and lower part of the classification. If we focus on hospitals with a productivity index higher than one and examine their components, we find cases in which technological change is more relevant (e.g., Almirante, Horacio Díaz Gómez or José Domingo de Obaldía), but also others in which efficiency change prevails (Azuero Anita Moreno, Changuinola, San Miguel Arcángel or Gustavo Nelson Collado). Nevertheless, as for the hospitals with lower average MPI values (Joaquín Pablo Franco, Ezequiel Abadía and Cecilio A. Astillero), all of them show higher values in the EC component, which may indicate that these hospitals have made less effort in terms of investment.

With respect to the values of the confidence intervals, in the nine hospitals with a higher MPI score we observe that almost all present lower values are above 1, so we can consider these estimates to be sufficiently robust. For the rest of hospitals, the estimated intervals include the value 1, which implies that the estimates obtained are not significant. This problem is much greater if we look at the estimated values for each of the components, in which the oscillation is much greater, thus it is impossible to find an estimate that can be considered as significant. Therefore, as mentioned earlier, we need to be cautious when interpreting the results derived from the average decompositions. 
Table 9. Mean values of MPI and their components for each hospital (2005-2015)

\begin{tabular}{|c|c|c|c|c|c|c|c|c|c|c|}
\hline System & Hospital & MPI & $\begin{array}{l}\text { Lower } \\
\text { Bound }\end{array}$ & $\begin{array}{l}\text { Upper } \\
\text { Bound }\end{array}$ & EC & $\begin{array}{l}\text { Lower } \\
\text { Bound }\end{array}$ & $\begin{array}{l}\text { Upper } \\
\text { Bound }\end{array}$ & TC & $\begin{array}{l}\text { Lower } \\
\text { Bound }\end{array}$ & $\begin{array}{l}\text { Upper } \\
\text { Bound }\end{array}$ \\
\hline SSF & Hospital de Especialidades Pediatrica Omar Torrijos Herrera & 1.1341 & 1.0525 & 1.3378 & 1.0489 & 0.7875 & 1.4774 & 1.0590 & 0.8193 & 1.3920 \\
\hline SSF & Hospital de Almirante & 1.0924 & 1.0721 & 1.1133 & 1.0000 & 0.7813 & 1.2900 & 1.0924 & 0.8575 & 1.4002 \\
\hline $\mathrm{MoH}$ & Hospital Regional de Azuero Anita Moreno & 1.0860 & 1.0309 & 1.1332 & 1.0770 & 0.8754 & 1.2558 & 1.0070 & 0.8695 & 1.2469 \\
\hline SSF & Hospital de Changuinola & 1,0807 & 1.0387 & 1.1427 & 1.0375 & 0.9942 & 1.0731 & 1.0151 & 0.8822 & 1.2209 \\
\hline $\mathrm{MoH}$ & Hospital San Miguel Arcangel & 1.0426 & 1.0243 & 1.0601 & 1.0319 & 0.8656 & 1.1891 & 1.0148 & 0.8790 & 1.2051 \\
\hline SSF & Policlinica Especializada Dr. Horacio Diaz Gomez & 1.0326 & 0.9966 & 1.0830 & 1.0000 & 0.7859 & 1.3207 & 1.0326 & 0.7965 & 1.3253 \\
\hline SSF & Hospital Dr. Gustavo Nelson Collado (Chitre) & 1.0290 & 1.0073 & 1.0717 & 1.0343 & 0.8331 & 1.2311 & 1.0177 & 0.8558 & 1.2616 \\
\hline SSF & Hospital Regional Dr. Rafael Hernandez & 1.0265 & 1.0067 & 1.0651 & 1.0161 & 0.8535 & 1.2019 & 1.0210 & 0.8669 & 1.2161 \\
\hline SSF & Complejo Hospitalario Metropolitano Arnulfo A. Madrid & 1.0227 & 1.0094 & 1.0399 & 0.9946 & 0.7997 & 1.2162 & 1.0331 & 0.8463 & 1.2863 \\
\hline $\mathrm{MoH}$ & Hospital Materno Infantil Jose Domingo de Obaldia & 1.0217 & 0.9740 & 1.0566 & 0.9862 & 0.8196 & 1.1538 & 1.0412 & 0.8823 & 1.2672 \\
\hline $\mathrm{MoH}$ & Hospital San José de La Palma & 1.0185 & 0.9798 & 1.0487 & 1.0020 & 0.8368 & 1.1556 & 1.0190 & 0.8798 & 1.2218 \\
\hline $\mathrm{MoH}$ & Hospital Luis Chicho Fabrega & 1.0135 & 0.9887 & 1.0386 & 1.0000 & 0.7893 & 1.2282 & 1.0135 & 0.8351 & 1.2831 \\
\hline SSF & Hospital Dr. Rafael Estevez & 1.0134 & 0.9580 & 1.0657 & 1.0117 & 0.8614 & 1.1533 & 1.0188 & 0.8850 & 1.1833 \\
\hline $\mathrm{MoH}$ & Hospital Rafael H. Moreno & 1.0116 & 0.9946 & 1.0389 & 1.0000 & 0.7903 & 1.2250 & 1.0116 & 0.8320 & 1.2863 \\
\hline $\mathrm{MoH}$ & Hospital Santo Tomas & 1.0026 & 1.0001 & 1.0284 & 0.9912 & 0.8148 & 1.1789 & 1.0282 & 0.8607 & 1.2569 \\
\hline $\mathrm{MoH}$ & Hospital Del Niño & 1.0016 & 0.9896 & 1.0330 & 0.9755 & 0.8283 & 1.1551 & 1.0353 & 0.8758 & 1.2312 \\
\hline SSF & Hospital Dra. Susana Jones Cano & 0.9959 & 0.9717 & 1.0182 & 1.0000 & 0.7776 & 1.2198 & 0.9959 & 0.8245 & 1.2908 \\
\hline SSF & Hospital de Chiriqui Grande & 0.9904 & 0.9582 & 1.0350 & 1.0000 & 0.8031 & 1.2496 & 0.9904 & 0.8130 & 1.2341 \\
\hline $\mathrm{MoH}$ & Hospital Dr. Aquilino Tejeira & 0.9895 & 0.9617 & 1.0232 & 0.9933 & 0.7743 & 1.2082 & 0.9967 & 0.8260 & 1.2928 \\
\hline $\mathrm{MoH}$ & Hospital Dr. Joaquin Pablo Franco & 0.9893 & 0.9308 & 1.0350 & 0.9876 & 0.8026 & 1.1788 & 1.0148 & 0.8569 & 1.2199 \\
\hline SSF & Hospital Ezequiel Abadia & 0.9836 & 0.9247 & 1.0390 & 0.9732 & 0.8108 & 1.1618 & 1.0368 & 0.8733 & 1.2133 \\
\hline $\mathrm{MoH}$ & Hospital Dr. Cecilio A. Castillero & 0.9788 & 0.9351 & 1.0418 & 0.9718 & 0.8062 & 1.1703 & 1.0219 & 0.8571 & 1.2131 \\
\hline
\end{tabular}




\section{Discussion}

Our results suggest that hospitals belonging to the SSF outperformed Ministry's hospitals throughout the period studied. According to the values of the Malmquist indices, the former experienced, on average, a productivity growth close to $4 \%$ during the period analyzed, while Ministry's hospitals only registered an increase of $1.5 \%$. Moreover, the estimated confidence intervals confirm that the growth of productivity experienced by hospitals belonging to the SSF was significantly higher. Actually, if we examine specific hospital cases, we observe that eight hospitals shows significant progress in MPI over the period, six of which belong to SSF.

The fundamental factor that, in principle, explains these results is the superior growth of technological change in SSF hospitals, especially in the final years of the period, since average efficiency growth has been very low in both systems. This result is not surprising, since it is well known in the country that the hospitals belonging to the Social Security Fund made a greater investment effort to improve their resource endowment during the period. However, it is not possible to statistically conclude that the MPI growth experienced by those hospitals can be attributed to technological change because the confidence intervals of this component, as well as for the efficiency change, are very wide and include the unity. This reveals that there is still a certain level of uncertainty regarding productivity change and its components in the Panamanian public health care system.

Our results demonstrate that we need to be careful when solely considering results from the original sample, especially if the sample size is not too large as in our case, without making statistical inferences (e.g. using bootstrapping techinques). This is something that has been already pointed out in some previous studies conducted in other fields of research [51, for example], which is becoming an increasingly common practice when analyzing the efficiency of hospitals $[18,52]$.

Despite the interesting findings derived from the analysis carried out, we are aware that this study can still be improved and extended in a number of directions. The first limitation is the limited number of hospitals available in our dataset, which we should try to expand in future studies so that the results obtained reflect in the most reliable 
way possible the reality of the country's public hospital system. Second, as well as many other previous studies conducted in developing countries, we were unable to collect data on the case mix of each hospital or patient outcome quality. Thus, we did not determine whether a few variations in the severity of cases treated in each hospital are possible. This can be a relevant issue according to the results obtained by Chowdhury et al. [53] Therefore, in future studies we should attempt to incorporate data on both the case-mix and the quality of care if such data become available. Finally, we have not explored the potential influence of environmental factors on hospitals' performance. This could be addressed in a further analysis using a two-stage approach to improve the reliability of the results. Despite these limitations, this study can be considered a beneficial attempt to measure the efficiency and productivity of public hospitals in Panama for the first time.

\section{Conclusions}

This study provides an empirical representation of the efficiency and productivity changes of public hospitals in Panama. The completion of this evaluation has required the collection of a large amount of information, since the health system of this country did not have a systematized database of records, as is usual in most developed countries. Therefore, one of the main contributions of this work has been precisely the development of an extensive database including multiple indicators on the resources employed and the activities carried out by 22 hospitals over an eleven-year period (2005-2015).

Our main analysis tool are Malmquist productivity indices (MPI), which allow the decomposition of productivity growth into measures of technical efficiency change, technological change and changes in scale. In addition we applied bootstrapping techniques to ascertain confidence intervals for estimators, so that we can test for statistical significance and derive more robust conclusions. The estimated MPI values showed that those hospitals experienced a productivity growth of $2.5 \%$, which mainly resulted from an increase in technological change, although this result cannot be corroborated after making statistical inference using bootstrapping techniques.

The main focus of our analysis has been placed on the comparison between the two coexisting public management systems, the Social Security Fund (SSF) and the Ministry 
of Health $(\mathrm{MoH})$. This dual structure is relatively common in Central American countries, where there is a social insurance system offering health care to the insured population and a national health system that guarantees coverage for the entire population and the whole territory, including areas with more difficult access. Specifically, our main interest was to determine to whether hospitals belonging to one system or the other has had a better performance over the period under analysis. The MPI values allow us to identify that SSF's hospitals outperformed Minitry's hospitals over the evaluated period. This result was corroborated by values of the confidence intervals estimated using bootstrap, thus our results on this issue seem to be quite consistent.

\section{$\underline{\text { Declarations }}$}

Ethics approval (include appropriate approvals or waivers)

Not applicable

Consent to participate (include appropriate statements)

The four authors agree with the contents of the manuscript

Availability of data and material (data transparency)

The datasets used and/or analysed during the current study are available from the corresponding author on reasonable request

\section{Conflicts of interest}

The four authors declare that they have no conflict of interest to declare.

\section{Competing interests}

The authors declare that they have no competing interests.

\section{Funding}

This research has been conducted thanks to the financial support from the Junta de Extremadura through grants IB16171 and GR18106.

\section{Authors' contribution}

The four authors have contributed to the design, analysis, discussion, writing, and critical review of the paper, and give evidence of the originality and consent to publication.

Code availability (software application or custom code)

All calculations have been conducted using different packages of software $\mathrm{R}$

\section{Acknowledgments}

The authors acknowledge the helpful comments received from Daniel Santín (Complutense University) and Rafaela Dios (University of Córdoba). Likewise, Jose M. Cordero and Cristina Polo thank the financial support from the Junta de Extremadura through grants IB16171 and GR18106. 


\section{References}

[1] Moreno-Serra R, Anaya-Montes M, Smith PC. Potential determinants of health system efficiency: Evidence from Latin America and the Caribbean. Plos One. 2019;14(5).

[2] Medici A, Lewis M. Health Policy and Finance Challenges in Latin America and the Caribbean: An Economic Perspective. In Oxford Research Encyclopedia of Economics and Finance. 2019. doi: 10.1093/acrefore/9780190625979.013.24

[3] Hollingsworth B, Dawson PJ, Maniadakis N. Efficiency measurement of health care: a review of non-parametric methods and applications. Health Care Manag Sci. 1999;2(3):161-172.

[4] Worthington AC. Frontier efficiency measurement in health care: a review of empirical techniques and selected applications. Medical Care Res Rev. 2004;61(2):135170.

[5] Ozcan YA. Performance measurement using data envelopment analysis (DEA). In Ozcan YA (ed.). Health Care Benchmarking and Performance Evaluation Boston: Springer; 2007.

[6] Hollingsworth B. The measurement of efficiency and productivity of health care delivery, Health Econ. 2008;17(10):1107-1128.

[7] Linna M. Health care financing reform and the productivity change in Finnish hospitals, J Health Care Fin. 1999;26(3):83-100.

[8] Castro-Lobo MS, Ozcan YA, da Silva AC, Lins MPE, Fiszman R. Financing reform and productivity change in Brazilian teaching hospitals: Malmquist approach, Central Eur J Oper Res. 2010;18(2):141-152.

[9] Chang SJ, Hsiao HC, Huang LH, Chang H. Taiwan quality indicator project and hospital productivity growth, Omega. 2011;39(1):14-22.

[10] Färe R, Grosskopf S, Lindgren B, Roos P. Productivity Developments in Swedish Hospitals: A Malmquist Output Index Approach, in Charnes A, Cooper WW, Lewin AY, Seiford LM (eds.) Data Envelopment Analysis: Theory, Methodology and Applications, Boston: Kluwer Academic Publishers; 1994.

[11] Grosskopf S. Some remarks on productivity and its decompositions, J Prod Anal. 2003;20: 459-74.

[12] Lovell CAK. The decomposition of Malmquist productivity indexes, J Prod Anal. 2003;20:437-58.

[13] Ray SC, Desli E. Productivity growth, technical progress, and efficiency change in industrialized countries: Comment, American Econ Rev. 1997;87:1033-39. 
[14] Lothgren M, Tambour M. Bootstrapping the data envelopment analysis Malmquist productivity index. App Econ. 1999;31(4):417-425.

[15] Simar L, Wilson PW. Estimating and bootstrapping Malmquist indices. Eur J Oper Res. 1999;115(3):459-471.

[16] Simar L, Wilson PW. A general methodology for bootstrapping in non-parametric frontier models. J App Statistics. 2000;27(6):779-802.

[17] Chowdhury H, Wodchis W, Laporte A. Efficiency and technological change in health care services in Ontario: An application of Malmquist Productivity Index with bootstrapping, Int J Prod Performance Manage. 2011;60(7):721-745.

[18] Cheng Z, Cai M, Tao H, He Z, Lin X, Lin H, Zuo Y. Efficiency and productivity measurement of rural township hospitals in China: A bootstrapping data envelopment analysis. BMJ open, 6(11), e011911. 2016. doi: 10.1136/bmjopen-2016-011911.

[19] Ferreira D, Marques RC. Did the corporatization of Portuguese hospitals significantly change their productivity?. Eur J Health Econ. 2015;16(3):289-303.

[20] Bannick RR, Ozcan YA. Efficiency analysis of federally funded hospitals: comparison of DoD and VA hospitals using data envelopment analysis. Health Serv Manage Res. 1995;8(2):73-85.

[21] Maniadakis N, Hollingsworth B, Thanassoulis E. The impact of the internal market on hospital efficiency, productivity and service quality. Health Care Manag Sci. 1999;2:75-85

[22] Biørn E, Hagen TP, Iversen T, Magnussen J. The effect of activity-based financing on hospital efficiency: a panel data analysis of DEA efficiency scores 1992-2000. Health Care Manag Sci. 2003;6(4), 271-283.

[23] Blank J, Eggink E. The impact of policy on hospital productivity: a time series analysis of Dutch hospitals. Health Care Manag Sci. 2014;17:139-149.

[24] Rego G, Nunes R, Costa J. The challenge of corporatisation: the experience of Portuguese public hospitals. Eur J Health Econ. 2010;11(4):367-381.

[25] Ozcan YA, Luke RD, Haksever C. Ownership and organizational performance: A comparison of technical efficiency across hospital types. Medical Care. 1992;30(9):781794.

[26] Burgess Jr JF, Wilson PW. Hospital ownership and technical inefficiency. Manage Sci. 1996;42(1):110-123.

[27] Chang H, Cheng MA, Das S. Hospital ownership and operating efficiency: evidence from Taiwan. Eur J Oper Res. 2004;159:513-527. 
[28] Herr A. Cost and technical efficiency of German hospitals: does ownership matter? Health Econ. 2008;17:1057-1071.

[29] Mutter RL, Rosko MD. The impact of ownership on the cost efficiency of U.S hospitals. Adv Health Econ Health Serv Res. 2008;18:113-138.

[30] Farsi M, Filippini M. Effects of ownership, subsidization and teaching activities on hospital costs in Switzerland. Health Econ. 2008;17:335-350.

[31] Chen KC, Chen HM, Chien LN, Yu MM. Productivity growth and quality changes of hospitals in Taiwan: does ownership matter?, Health Care Manag Sci. 2019;22(3):451-461.

[32] O’Neill L, Rauner M, Heidenberger K, Kraus M. A cross-national comparison and taxonomy of DEA-based hospital efficiency studies. Socio Econ Plan Sci. 2008;42(3): 158-189.

[33] Jehu-Appiah C, Sekidde S, Adjuik M, Akazili J, Almeida SD, Nyonator F, Baltussen R, Zere Asbu E, Muthuri-Kirigia J. Ownership and technical efficiency of hospitals: evidence from Ghana using data envelopment analysis. Cost Effectiveness and Resource Allocation. 2014;12(1):9.

[34] Şahin, B, İlgün, G. Assessment of the impact of public hospital associations (PHAs) on the efficiency of hospitals under the ministry of health in Turkey with data envelopment analysis. Health Care Manage Sci. 2019;22(3), 437-446.

[35] Arocena P, García-Prado A. Accounting for quality in the measurement of hospital performance: evidence from Costa Rica. Health Econ. 2007;16(7):667-685.

[36] Giménez V, Keith JR, Prior D. Do healthcare financing systems influence hospital efficiency? A metafrontier approach for the case of Mexico. Health Care Manag Sci. 2019;22(3):549-559.

[37] Giménez V, Prieto W, Prior D, Tortosa-Ausina E. Evaluation of efficiency in Colombian hospitals: An analysis for the post-reform period. Socio Econ Plan Sci. 2019;65:20-35.

[38] Kohl S, Schoenfelder J, Fügener A, Brunner JO. The use of Data Envelopment Analysis (DEA) in healthcare with a focus on hospitals. Health Care Manag Sci. 2019;22(2):245-286.

[39] Bogetoft P, Otto L. Benchmarking with DEA, SFA, and R. Int Series Oper Res Manage Sci. 2011;157:1-35.

[40] Caves DW, Christensen LR, Diewert WE. The economic theory of index numbers and the measurement of input, output, and productivity. Econometrica. 1982;50(6):1393-1414. 
[41] Färe R, Grosskopf S, Lindgren B, Roos P. Productivity changes in Swedish pharamacies 1980-1989: A non-parametric Malmquist approach, Springer Netherlands. 1992. (pp. 81-97).

[42] Jacobs R, Smith PC, Street A. Measuring efficiency in health care: analytic techniques and health policy, London: Cambridge University Press; 2006.

[43] Barros CP, De Menezes AG, Peypoch N, Solonandrasana B, Vieira JC. An analysis of hospital efficiency and productivity growth using the Luenberger indicator. Health Care Manag Sci. 2008;11(4):373.

[44] Färe R, Grosskopf S, Norris M, Zhang Z. Productivity growth, technical progress, and efficiency change in industrialized countries, American Econ Rev. 1994;84:66-83.

[45] Balk BM. Scale efficiency and productivity change, J Prod Anal. 2001;15(3):159183.

[46] Efron B. Bootstrap methods: another look at the jackknife. Annals of Statistics. $1979 ; 7: 1-16$

[47] Efron B, Tibshirani RJ. An introduction to the bootstrap. London: Chapman \& Hall; 1993.

[48] Simar L, Wilson PW. Sensitivity analysis of efficiency scores: How to bootstrap in nonparametric frontier models, Manage Sci. 1998;44(1):49-61.

[49] Chilingerian JA, ShermanHD. Health care applications from hospitals to physicians; from productive efficiency to quality frontiers. In: CooperW, Seiford LM, Zhu J (eds) Handbook on data envelopment analysis. Dordrecht: Kluwer; 2004.

[50] Giancotti M, Pipitone V, Mauro M, Guglielmo A. 20 Years of Studies on Technical and Scale Efficiency in the Hospital Sector: a Review of Methodological Approaches. Int J Business Manage Invention. 2016;5(3):34-54.

[51] Odeck J. Statistical precision of DEA and Malmquist indices: A bootstrap application to Norwegian grain producers. Omega. 2009;37(5):1007-1017.

[52] Valdmanis V, Rosko M, Mancuso P, Tavakoli M, Farrar S. Measuring performance change in Scottish hospitals: a Malmquist and times-series approach. Health Serv Outcomes Res Method. 2017;17(2):113-126.

[53] Chowdhury H, Zelenyuk V, Laporte A, Wodchis WP. Analysis of productivity, efficiency and technological changes in hospital services in Ontario: How does casemix matter?. Int J Prod Econ. 2014;150:74-82. 


\section{APPENDIX}

Table A1. Hospitals included in the sample and their main characteristics

\begin{tabular}{|c|c|c|c|c|c|}
\hline Hospital & Network & Province & District & $\begin{array}{c}\text { Level of } \\
\text { complexity }\end{array}$ & Area of influence \\
\hline Hospital Santo Tomas & $\mathrm{MoH}$ & Panamá & Panamá & III & Regional \\
\hline Hospital Del Niño & $\mathrm{MoH}$ & Panamá & Panamá & III & Urban \\
\hline Hospital de Especialidades Pediátricas Omar Torrijos Herrera & SSF & Panamá & Panamá & III & Rural \\
\hline Complejo Hospitalario Dr. Arnulfo Arias Madrid & SSF & Panamá & Panamá & III & Urban \\
\hline Hospital Dra. Susana Jones Cano & SSF & Panamá & San Miguelito & II & Urban \\
\hline Hospital San Miguel Arcangel & $\mathrm{MoH}$ & Panamá & San Miguelito & II & Urban \\
\hline Hospital de Changuinola & SSF & Bocas del Toro & Changuinola & II & Rural \\
\hline Hospital de Almirante & SSF & Bocas del Toro & Changuinola & I-II & Rural \\
\hline Hospital de Chiriquí Grande & SSF & Bocas del Toro & Chiriquí Grande & I-II & Rural \\
\hline Hospital Regional Dr. Rafael Hernandez & SSF & Chiriquí & David & II & Regional \\
\hline Hospital Dr. Cecilio A. Castillero & $\mathrm{MoH}$ & Herrera & Chitre & II & Urban \\
\hline Hospital Ezequiel Abadia & SSF & Veraguas & Sona & I-II & Urban \\
\hline Policlinica Especializada Dr. Horacio Diaz Gomez & SSF & Veraguas & Santiago & II & Urban \\
\hline Hospital Dr. Rafael Estevez & SSF & Coclé & Aguadulce & II & Urban \\
\hline Hospital Dr. Aquilino Tejeira & $\mathrm{MoH}$ & Coclé & Penonomé & II & Regional \\
\hline Hospital San José de la Palma & $\mathrm{MoH}$ & Darién & Chepigana & I-II & Urban \\
\hline Hospital Regional de Azuero Anita Moreno & $\mathrm{MoH}$ & Los Santos & La Villa de Los Santos & II & Regional \\
\hline Hospital Rafael H. Moreno & $\mathrm{MoH}$ & Los Santos & Macaracas & II & Rural \\
\hline Hospital Dr. Gustavo Nelson Collado & SSF & Herrera & Chitre & II & Regional \\
\hline Hospital Luis Chicho Fabrega & $\mathrm{MoH}$ & Veraguas & Santiago & II & Regional \\
\hline Hospital Materno Infantil Jose Domingo de Obaldia & $\mathrm{MoH}$ & Chiriquí & David & III & Regional \\
\hline Hospital Dr. Joaquin Pablo Franco Sayas & $\mathrm{MoH}$ & Los Santos & Las Tablas & II & Regional \\
\hline
\end{tabular}


Table A2. Descriptive statistics of the Malmquist index and its components by year

\begin{tabular}{|c|c|c|c|c|c|c|c|c|c|c|}
\hline Malmquist & $2005-2006$ & 2006-2007 & $2007-2008$ & 2008-2009 & $2009-2010$ & 2010-2011 & 2011-2012 & $2012-2013$ & 2013-2014 & 2014-2015 \\
\hline Mean & 0.9784 & 0.9708 & 1.0552 & 1.0077 & 0.9419 & 1.0689 & 1.0525 & 1.0151 & 1.1593 & 1.1396 \\
\hline SD & 0.0865 & 0.1196 & 0.1000 & 0.0975 & 0.1175 & 0.1517 & 0.1287 & 0.1288 & 0.6770 & 0.3216 \\
\hline Min & 0.8506 & 0.6483 & 0.8891 & 0.8661 & 0.6286 & 0.8409 & 0.6621 & 0.7634 & 0.8750 & 0.8842 \\
\hline Max & 1.2196 & 1.2841 & 1.2466 & 1.3412 & 1.1487 & 1.5448 & 1.3335 & 1.4485 & 1.5645 & 1.3565 \\
\hline Efficiency & $2005-2006$ & 2006-2007 & $2007-2008$ & 2008-2009 & $2009-2010$ & 2010-2011 & 2011-2012 & $2012-2013$ & 2013-2014 & 2014-2015 \\
\hline Mean & 1.0640 & 0.9844 & 0.9956 & 1.0117 & 0.9849 & 0.8969 & 1.0125 & 0.9968 & 1.0372 & 1.1280 \\
\hline SD & 0.0932 & 0.1022 & 0.1074 & 0.0795 & 0.1119 & 0.1469 & 0.1181 & 0.0689 & 0.1555 & 0.2192 \\
\hline Min & 0.9471 & 0.6646 & 0.6940 & 0.8315 & 0.6351 & 0.6472 & 0.8352 & 0.8092 & 0.9169 & 0.8888 \\
\hline $\operatorname{Max}$ & 1.2927 & 1.1408 & 1.2491 & 1.1659 & 1.1710 & 1.0971 & 1.3662 & 1.1124 & 1.3598 & 1.2809 \\
\hline Pure Efficiency & $2005-2006$ & 2006-2007 & $2007-2008$ & 2008-2009 & $2009-2010$ & $2010-2011$ & 2011-2012 & 2012-2013 & 2013-2014 & 2014-2015 \\
\hline Mean & 1.0230 & 0.9866 & 1.0181 & 0.9804 & 0.9863 & 1.0279 & 1.0056 & 0.9995 & 1.0326 & 1.0842 \\
\hline SD & 0.0666 & 0.0714 & 0.1048 & 0.0768 & 0.0764 & 0.1808 & 0.1094 & 0.0791 & 0.1475 & 0.1912 \\
\hline Min & 0.9193 & 0.8026 & 0.8864 & 0.7358 & 0.7747 & 0.7454 & 0.6993 & 0.8053 & 0.8823 & 0.8747 \\
\hline Max & 1.2434 & 1.1384 & 1.3590 & 1.1467 & 1.1138 & 1.7628 & 1.2668 & 1.2331 & 1.4173 & 1.4419 \\
\hline Technological Change & $2005-2006$ & $2006-2007$ & $2007-2008$ & $2008-2009$ & $2009-2010$ & 2010-2011 & 2011-2012 & $2012-2013$ & 2013-2014 & 2014-2015 \\
\hline Mean & 0.9208 & 0.9852 & 1.0672 & 0.9988 & 0.9579 & 1.2137 & 1.0452 & 1.0189 & 1.0771 & 1.0068 \\
\hline SD & 0.0493 & 0.0420 & 0.1204 & 0.0950 & 0.0683 & 0.2001 & 0.1214 & 0.1145 & 0.3261 & 0.1647 \\
\hline Min & 0.7878 & 0.9348 & 0.8891 & 0.9112 & 0.8028 & 0.8409 & 0.6621 & 0.8758 & 0.9183 & 0.8814 \\
\hline Max & 0.9994 & 1.1514 & 1.4928 & 1.3412 & 1.0576 & 1.5554 & 1.2249 & 1.4485 & 1.5091 & 1.5310 \\
\hline Pure Technological Change & $2005-2006$ & 2006-2007 & $2007-2008$ & 2008-2009 & $2009-2010$ & 2010-2011 & 2011-2012 & $2012-2013$ & 2013-2014 & 2014-2015 \\
\hline Mean & 0.9211 & 0.9912 & 1.0477 & $\mathbf{1 . 0 4 1 7}$ & 0.9514 & 1.0633 & 0.9984 & $\mathbf{1 . 1 1 2 3}$ & $\mathbf{1 . 0 3 6 4}$ & $\mathbf{1 . 0 2 7 5}$ \\
\hline SD & 0.3360 & 0.3230 & 0.3289 & 0.4092 & 0.3038 & 0.3489 & 0.3284 & 0.4973 & 0.4463 & 0.3405 \\
\hline Min & 0.7515 & 0.7000 & 0.8118 & 0.7431 & 0.7280 & 0.6344 & 0.4322 & 0.8849 & 0.6898 & 0.8837 \\
\hline Max & 1.0615 & 1.4376 & 1.2249 & 1.6317 & 1.2268 & 1.3814 & 1.2116 & 1.4148 & 1.4336 & 1.5828 \\
\hline Scale Efficiency & $2005-2006$ & 2006-2007 & $2007-2008$ & 2008-2009 & $2009-2010$ & 2010-2011 & 2011-2012 & $2012-2013$ & 2013-2014 & 2014-2015 \\
\hline Mean & 1.0431 & 0.9973 & 0.9852 & 1.0358 & 0.9968 & 0.8842 & 1.0090 & 1.0002 & 1.0044 & 1.0394 \\
\hline SD & 0.1070 & 0.0761 & 0.1253 & 0.0928 & 0.0656 & 0.1509 & 0.0716 & 0.0654 & 0.0339 & 0.0579 \\
\hline Min & 0.9609 & 0.7781 & 0.6588 & 0.8315 & 0.8198 & 0.5538 & 0.8697 & 0.7531 & 0.9643 & 0.9913 \\
\hline Max & 1.3722 & 1.1282 & 1.2257 & 1.3338 & 1.1230 & 1.0934 & 1.2056 & 1.1103 & 1.0999 & 1.2049 \\
\hline Scale Technological Change & $2005-2006$ & 2006-2007 & $2007-2008$ & 2008-2009 & $2009-2010$ & 2010-2011 & 2011-2012 & $2012-2013$ & 2013-2014 & 2014-2015 \\
\hline Mean & 1.0061 & 1.0090 & 1.0334 & 0.9847 & 1.0179 & 1.1465 & 1.0613 & 0.9461 & 1.0528 & 0.9820 \\
\hline SD & 0.3696 & 0.3196 & 0.3305 & 0.3617 & 0.3180 & 0.3875 & 0.3354 & 0.3465 & 0.3212 & 0.2944 \\
\hline Min & 0.7430 & 0.8010 & 0.9042 & 0.8058 & 0.7839 & 0.8903 & 0.9309 & 0.5998 & 0.9570 & 0.8661 \\
\hline Max & 1.2555 & 1.3861 & 1.5046 & 1.2963 & 1.2737 & 1.5714 & 1.5320 & 1.0850 & 1.3818 & 1.0816 \\
\hline
\end{tabular}


Figures
(a) Discharges
(b) Emergency services
(c) Inputs
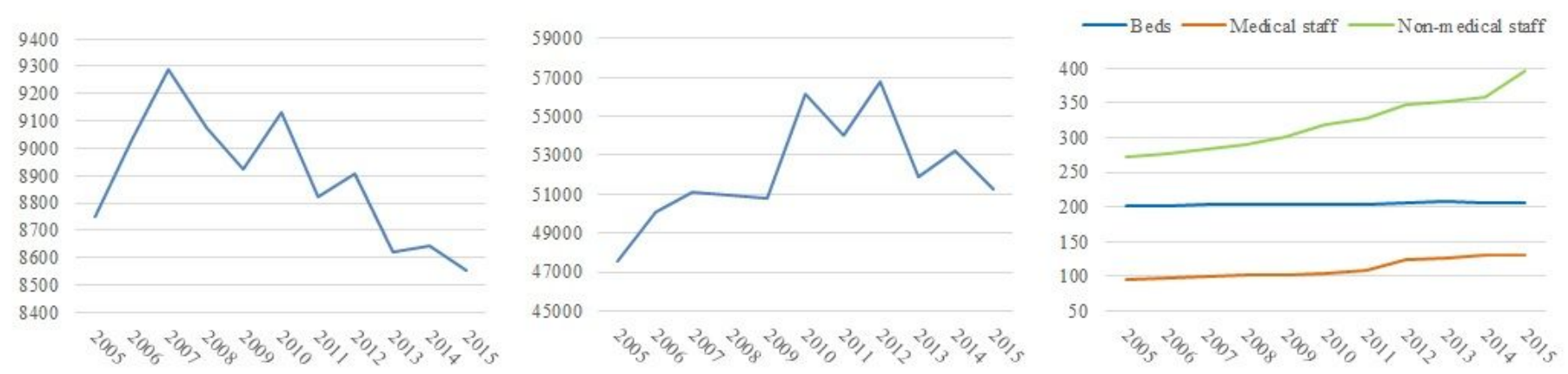

\section{Figure 1}

Evolution of average values over the period

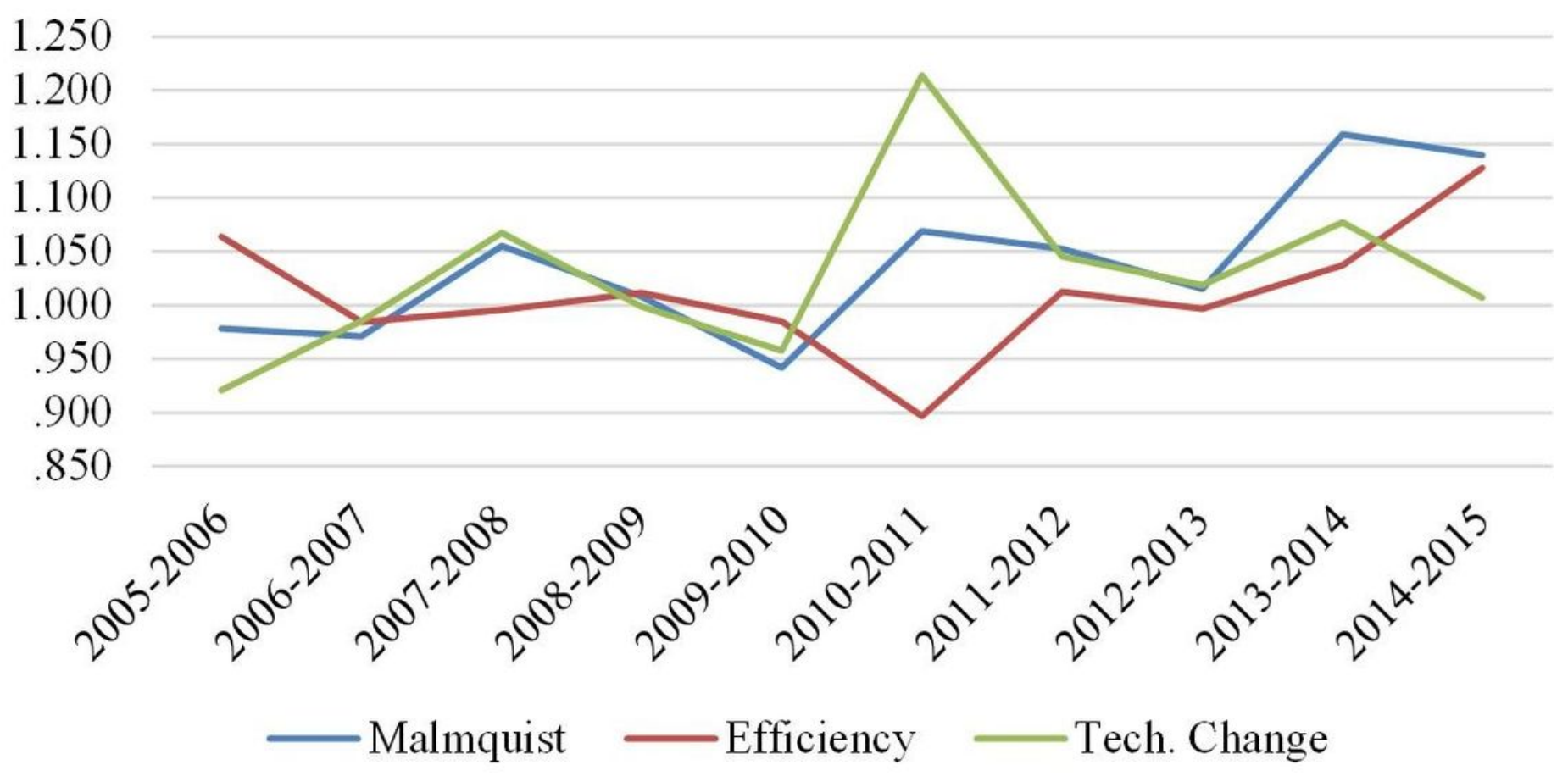

Figure 2

Evolution of the Malmquist Index and its main components (2005-2015) 


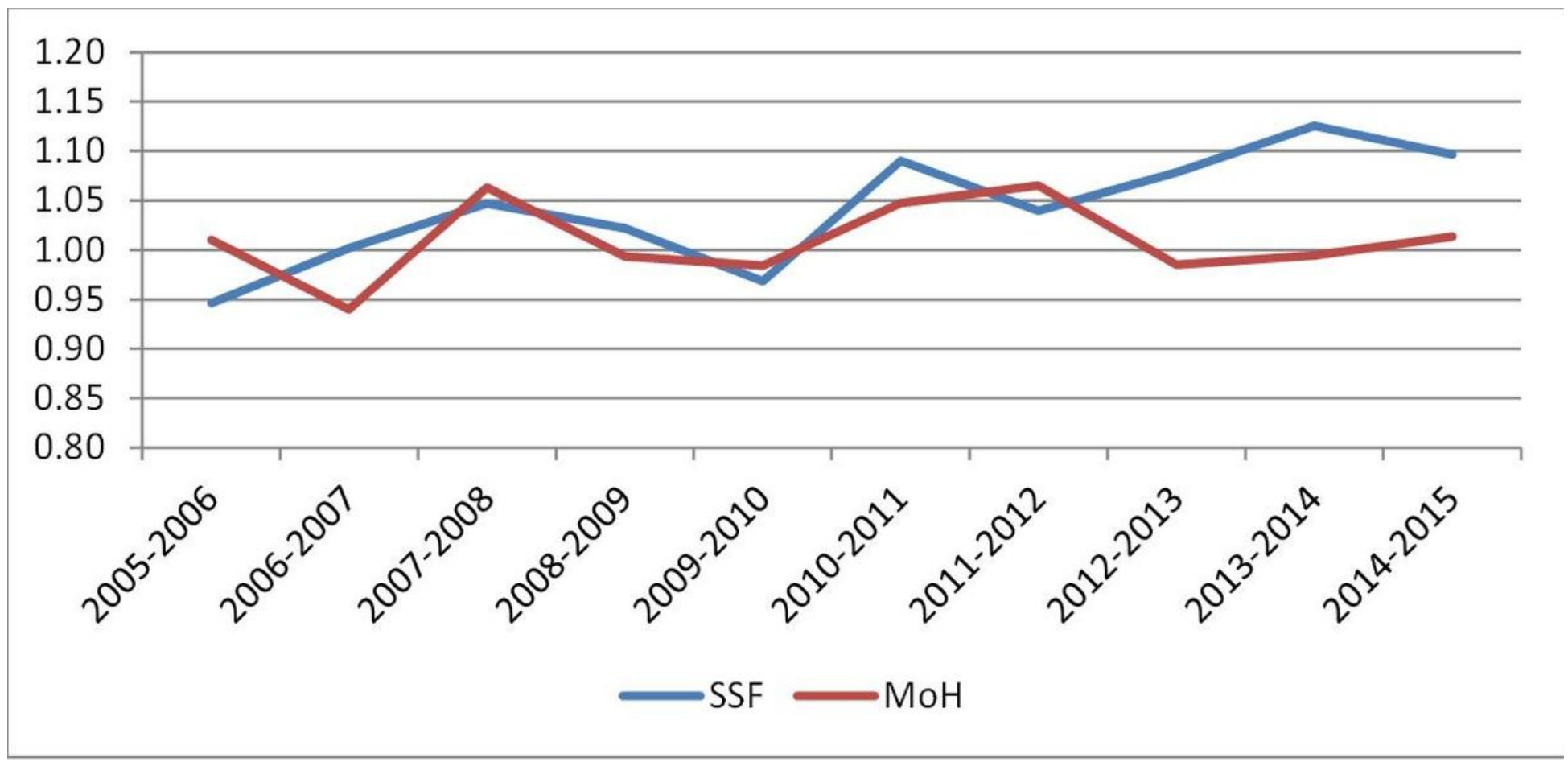

Figure 3

Evolution of MPI by type of management

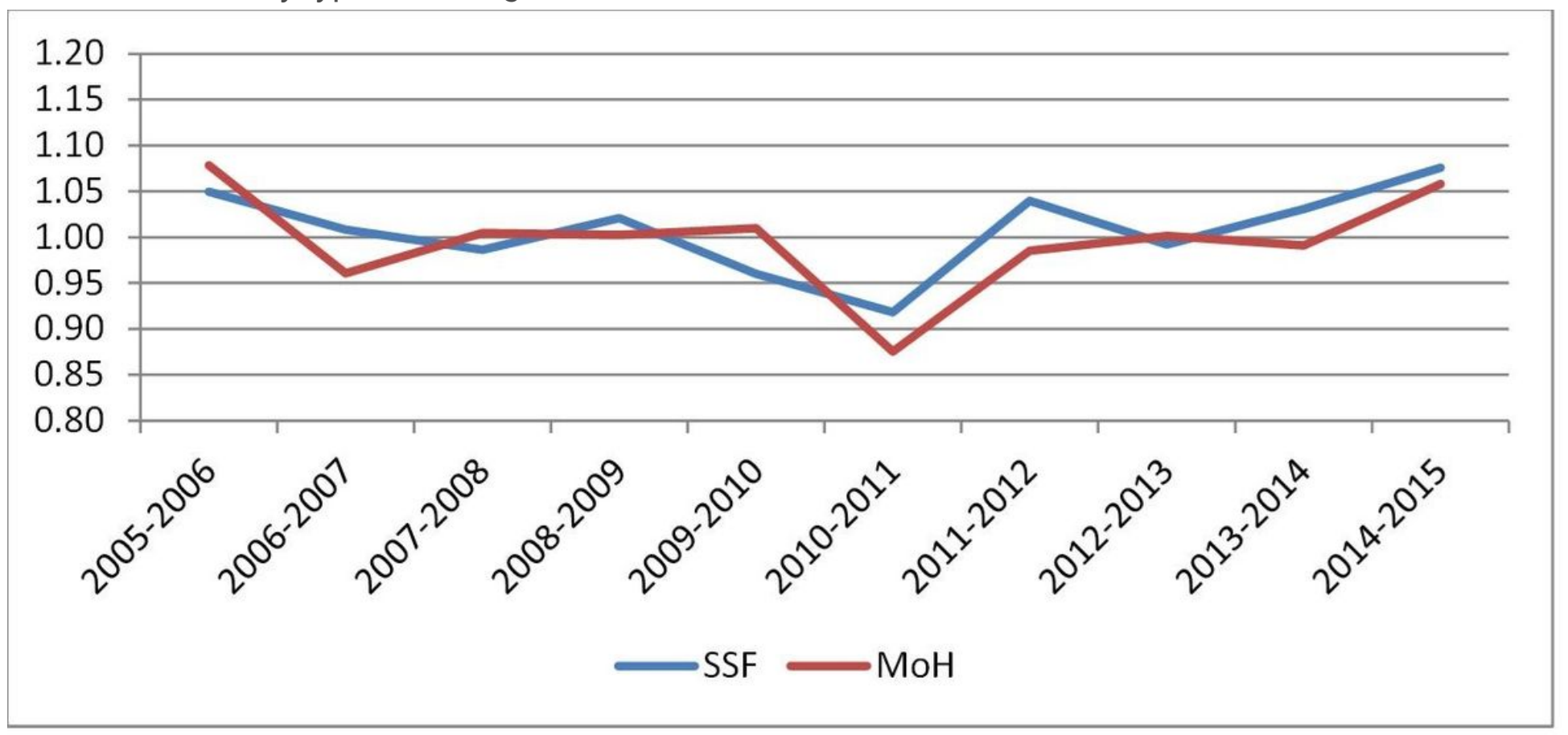

Figure 4

Evolution of EC by type of management 


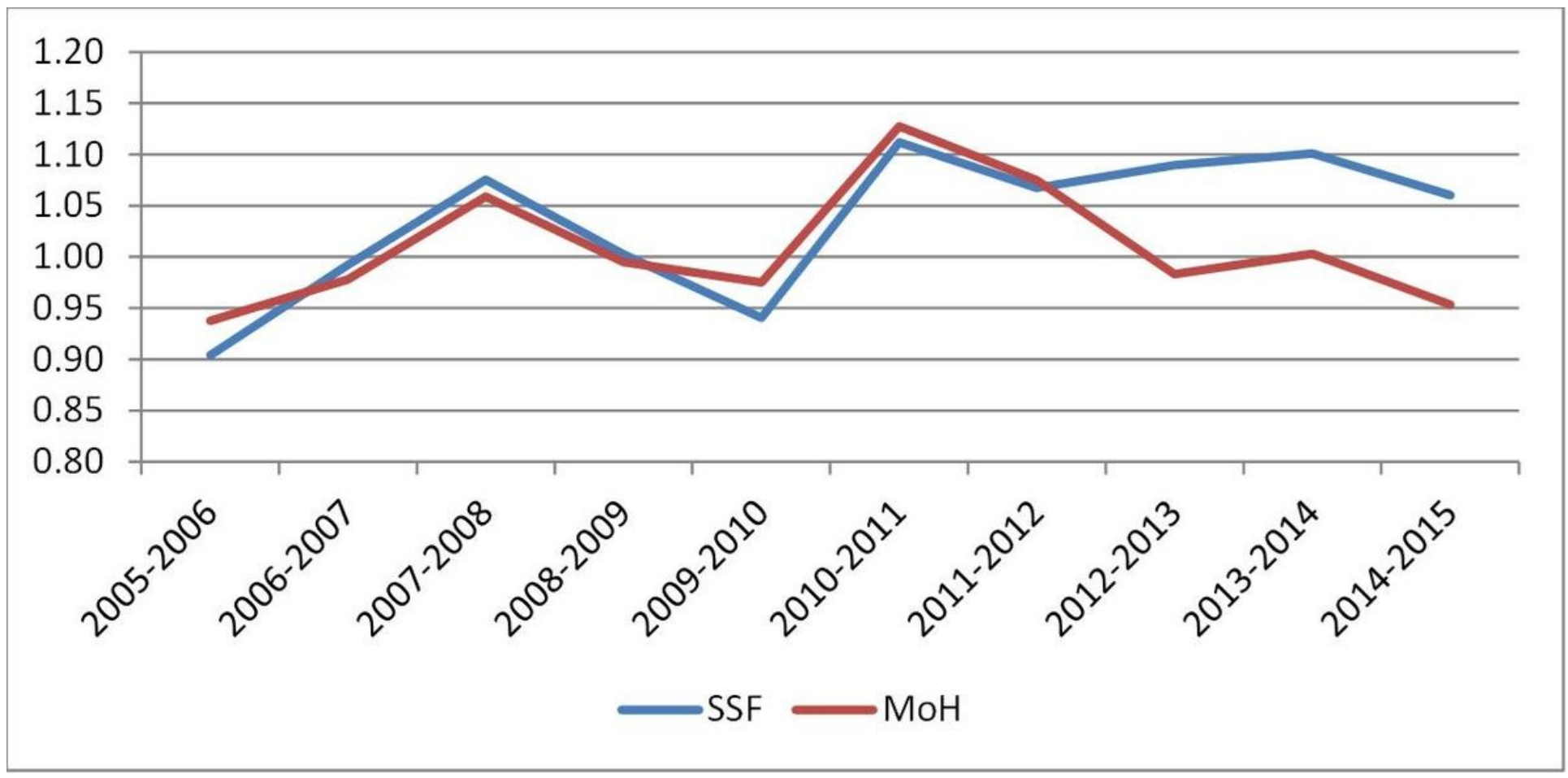

Figure 5

Evolution of TC by type of management 